\title{
Seasonal Forecasts for Asia: Global Model Experiments
}

\author{
Shyh-Chin Chen ${ }^{1, \star}$, Ming-Chin $W u^{2}$, and John O. Roads ${ }^{1}$
}

(Manuscript received 7 July 2000, in final form 10 January 2001)

\begin{abstract}
Since Sept. 26, 1997, the Scripps Experimental Climate Prediction Center (ECPC) has been making experimental, near real-time seasonal global forecasts with the National Centers for Environmental Prediction (NCEP) global spectral model used for the reanalysis. Images of these forecasts at seasonal time scales - are provided on the World Wide Web, and digital experimental forecast products are made available to interested researchers. In particular, these forecasts are now being used to drive a regional prediction model and various application models at National Taiwan University (NTU). Are these forecasts useful for Asia? What improvements could be made? The purpose of this paper is to describe briefly the global forecast and validating analysis system, various biases and errors in the forecasts for the Asia region, and the significance of the seasonal forecast over Asia, using two years of forecasts from October 1997 through October 1999. In particular, near-surface meteorological parameters, including temperature, precipitation, soil moisture, relative humidity, wind speed, and a fire weather index (a nonlinear combination of temperature, wind speed, and relative humidity) are skillful at weekly to seasonal time scales over much of the Asia region. Still, there are many improvements that can be made. The purpose of this paper is to provide a baseline for further development of the global model as well as various regional and specialized application models.
\end{abstract}

(Key words: Seasonal forecasts, Regional climate, Numerical prediction, General circulation model)

\section{INTRODUCTION}

The Scripps Experimental Climate Prediction Center (ECPC) has been making experimental, near real-time, long-range (up to 12 weeks) global dynamical forecasts since

\footnotetext{
${ }^{1}$ Experimental Climate Prediction Center, Scripps Institution of Oceanography, La Jolla,California, USA

${ }^{2}$ National Taiwan University, Taipei, Taiwan, ROC

* Corresponding author address: Dr. Shyh-Chin Chen, Experimental Climate Prediction Center, Scripps Institution of Oceanography, UCSD 0224, La Jolla,California, 92093, USA; E-mail: schen@ucsd.edu
} 
Sept. 26, 1997. Images from these forecasts are regularly shown on the ECPC world wide web (WWW) site (http://ecpc.ucsd.edu/) (see Roads et al. 2000b). In collaboration with National Taiwan University (NTU), regional images of these global forecasts are also displayed on a Taiwan site (http://wu.as.ntu.edu.tw/er.htm). In addition, digital products from the ECPC global forecasts are being provided as boundary conditions for a regional forecast model, which then makes higher resolution forecasts for Taiwan, which are also displayed on the NTU web site. These higher resolution forecasts are increasingly being used to reach out to various application users, who have continually demanded higher-resolution and longer lead-time forecasts than are currently available from operational meteorological agencies.

In order to set the stage for a subsequent evaluation of the regional model forecasts, we decided first to develop an analysis of the global forecast model skill. In a previous paper, Roads et al. (2001; hereafter referred to as RCF), discussed the global forecast skill in general but mainly focused on regional United States forecasts. Here we focus on the Asian region, which has similar yet somewhat unique problems compared to those in the United States region. Only by understanding where regional problems lie in the global model will we eventually understand how to enhance and properly utilize regional long-range predictions with both global and regional models.

Since these experimental long-range forecasts extend way beyond traditional atmospheric predictability limits (e.g., Lorenz 1965, 1982), it is important to stress that the foundation for this type of long-range prediction is based upon the interaction of the chaotic atmosphere with slowly varying boundary conditions. As discussed in RCF, persistent boundary conditions include anomalous sea-surface temperature anomalies (SSTAs), soil moisture, and snow. In that regard, it should be noted that slowly varying boundary conditions are externally provided to the global forecast model by persisting the initial SSTAs throughout the entire forecast. Internally, the model's slow varying soil wetness, which provides an intrinsic low frequency land forcing (especially during the summer when the surface fluxes are positive), may also be influential. In short, it is these persistent surface forcings that dynamical as well as statistical models are presumably exploiting in making skillful long-range predictions.

For example, numerous statistical methodologies (e.g., Bamston and Smith 1996; Ai and Chen 1998; Yuan and Wu 1998; Chu 1998) for making summer-season precipitation forecasts have previously shown the potential for making seasonal predictions for the Asia region. Although various cases of experimental long-range global numerical model prediction have been done in China (e.g., Wong and Zhou 1998), an overall evaluation for this region has yet to be demonstrated. The purpose here, then, is to evaluate the forecast skill, errors, and biases of two complete years (October 1997 through October 1999) of weekly to seasonal dynamical forecasts for the Asian region, which we believe will ultimately provide more useful utility than other long-range forecast methodologies. As will be shown, there is substantial skill in these long-range predictions. However, as noted by RCF, a major caveat is that our long-range forecasts during the evaluation period may be overly predictable, because of a strong El NinoSouthern Oscillation (ENSO) cycle. That is, there is strong and persistent tropical forcing associated with the large tropical sea-surface temperature anomalies, like the ones that occurred during the 1997/98 El Nino and 1998/99 La Nina. In fact, a number of papers have commented upon the increased predictability during previous events (see Barnston 1994; 
Brankovic et al. 1994; Kumar and Hoerling 1998). Other caveats about our evaluation will be discussed later.

In section 2, we briefly describe the global spectral model, as well as the initial conditions and validating analysis and our error and skill measures. Section 3 describes geographic characteristics of seasonal forecasts. Section 4 describes temporal characteristics of seasonal forecasts. Section 5 describes the average forecast skill of weekly to seasonal forecasts. Conclusions are provided in Section 6.

\section{METHODOLOGY}

\subsection{Global Spectral Model}

The global model used for this study is the National Centers for Environmental Prediction's (NCEP's) frozen version of the global spectral model (GSM; Kalnay et al. 1996; Roads et al. 1998,1999). This model, which has undergone steady improvement for a number of years (see Caplan et al. 1997), became on January 10, 1995, the basic global model used for the NCEP/ NCAR reanalysis (see Kalnay et al. 1996). A newer version of this model is used for four times daily global data assimilation system (GDAS) analysis and for making extended to medium-range (6-14 day) predictions.

Our particular version of the GSM uses spherical harmonics with a triangular truncation of T62 (roughly $200-\mathrm{km}$ resolution at equator) and 18 irregularly spaced vertical levels (L18T62). These levels are concentrated near the lower boundary and tropopause. Interested readers should refer to the RCF for a brief discussion of the model structure and physical packages. It should be noted that a number of more recent improvements have been implemented in NCEP models, which may ultimately prove useful in increasing the forecast skill (see Hong and Leetma 1999; Kanamitsu, personal communication). In that regard, it is our intention to eventually transmigrate our forecast system to a more recent version of the NCEP model and to re-examine the skill in the new system. It should also be noted that a regional spectral model (see Juang and Kanamitsu 1994; Chen et al. 1999; Anderson et al. 2000; Roads and Chen 2000), with the same basic parameterizations as the GSM, is also being used to make higher-resolution forecasts for the Taiwan region. The forecast skill of the higher-resolution regional forecast model will eventually be compared to the skill of this global model, as soon as we can obtain an adequate number of regional forecasts.

\subsection{Initial Conditions}

The initial conditions for the GSM forecasts come from the NCEP Global Data Assimilation System (GDAS) operational analysis (L28T126), which are posted in a timely fashion on a rotating disk archive at NCEP. We have managed to access these initial conditions almost every day for the 00UTC analysis from Sept. 27, 1997 to the present (L28T126 analyses were a vailable from 00UTC Sept. 27, 1997 to 00UTC Mar. 16, 2000; thereafter L42T170 became available). These higher resolution analyses are then transformed to lower resolution initial conditions (L18T62) by linearly interpolating between vertical sigma levels, spectrally trun- 
cating the spectral components, and bilinearly interpolating the higher resolution surface grids to our lower resolution grids (and land mask). We have also tried to access initial conditions for the 3 other analysis times $(06,12,18$ UTC) but had less success for various reasons.

The GSM is capable of changing the land-surface conditions (snow and soil moisture) and thus only initial conditions are needed over the land regions. However, ocean conditions must be specified during the course of a prediction. We change the SST climatological component continuously throughout the integration, and maintain the initial SSTA throughout the forecast integration. The sea-ice distribution is only changed climatologically. Obviously it is of interest eventually to use coupled ocean-atmosphere models as well as coupled land-atmosphere models to make seasonal predictions. Unfortunately, no coupled ocean-atmosphere model has yet been shown superior to simply persisting the SSTA for at least the first 12 weeks and using that as a boundary condition for the atmospheric model.

\subsection{Validating Analyses}

Although the operational GDAS analyses are sufficient to start our GSM forecasts, they are not sufficient to evaluate the desired forecast variables. For example, only atmospheric state variables such as temperature, humidity, winds, surface pressure, and surface state variables, such as soil moisture and snow, are available in the GDAS sigma files and surface files. Another (the so-called flux file) is developed from 6 hour forecasts with the MRF models, and contains near surface information, such as 2-meter temperature, humidity, 10-meter winds, surface latent, sensible, radiative fluxes and top of atmosphere radiation fluxes, and precipitation. These GDAS flux files were more difficult to access. Although we could have also used the NCEP reanalysis files to validate the model (and we did use these files to develop preliminary climatologies before we had the GDAS files), we were never able to access these files in as timely a manner as the GDAS files.

In order to extend backward the validation forecast period to the time when we first started archiving initial states, and to have available in near real time validating observations, we decided to develop our own flux files. Therefore, for our main validation effort, we now use one-day forecasts (the first forecast day of our 7-day forecasts made every day from 00 UTC analysis initial conditions). There are only three missing 00 UTC initial states in more than a two-year period and for these periods we used a previous two-day forecast to generate the associated daily flux files. These one-day forecasts are not exactly the same as the operational analysis, which is based upon $4 \times$ daily 6-hour forecasts from the latest high-resolution global model, or the reanalysis, which is based upon $4 \times$ daily 6-hour forecasts with our version of the model. Nevertheless they do form a useful approximation that can at least be used to estimate forecast skill upper bounds. As described in RCF, forecasts validated against these 1-day forecasts are slightly more skillful than forecasts validated against NCEP's operational analysis. In turn, forecasts validated against operational analysis are likely to be more skillful than forecasts validated against raw station observations. For future reference, the validating 1-day forecast analyses will be referred to as the V1 or 1-day forecast analysis. The more incomplete GDAS operational analysis (referred as VO) will not be used in this paper, but some comparisons to V1 were discussed by RCF. In particular, it was found that the validating characteris- 
tics using V1 and VO were very similar, except that VO produces somewhat lower skills and larger biases.

Although the 1-day forecast analysis validation set (V1) is certainly useful in the absence of other complete validating data sets, at least there are better approximations to the global precipitation. In particular, Xie and Arkin (1997) have developed a global precipitation data set that not only extends back to 1979 monthly means, but also provides higher temporal resolution pentad means. The Xie and Arkin data set comes mostly from satellite and gauge measurements (numerical weather prediction estimates are mainly used only in high latitudes to fill in missing grid points). These pentads were interpolated into weekly means (by first interpolating them into daily means and then subsequently accumulating the daily values into weekly means). This analysis will be referred to as the VX or Xie and Arkin analysis. It should be noted that other precipitation data sets, including some of the newer data sets being developed from the Tropical Rainfall Measuring Mission, were also utilized for some of the global forecast comparisons and that similar model forecast skill was found. Apparently, the forecast differences between our forecast model precipitation and the various precipitation data sets are larger than the variability among the data sets themselves.

\subsection{Forecasts}

Seven-day GSM forecasts are made every day, and digital files are ransferred to an anonymous ftp site in order to provide general information to interested researchers as well as to develop the basic 1-day validating analysis (V1). Here we examine the 12-week GSM forecasts, which are made only once a week (every weekend when the greatest computer capacity is available) as an extension to the daily forecasts. These 12-week forecasts are then archived into weekly averages, which can be further averaged into 3 monthly (4-week) averages and a seasonal (12-week) average. Because of limited archive capacity, we decided not to evaluate time scales of less than a week, at least initially. These 12-week forecasts are also used to drive associated regional models for the Taiwan region, which will be discussed in another paper.

\subsection{Skill Measures}

As discussed by RCF, we evaluate the forecasts by examining the average difference or bias of the forecasts:

$$
\text { Bias }=[F-O]=[F]-[O] \text {, }
$$

where [...] indicates a climatological average, which is time (monthly and forecast lag) dependent. $\mathrm{F}$ is the forecast average (weekly, monthly, seasonal) and $\mathrm{O}$ is the corresponding validating observation or analyses with the same time averages. The ensemble average can also be a spatially (cosine) weighted average

$$
\{\text { Bias }\}=\{[F]\}-\{[O]\},
$$

where $\{\ldots\}$ indicates the spatially (cosine) weighted average. See Figs. 1-4 for the Asian do- 
main used in this paper.

We develop climatological averages of weekly to seasonal forecasts since biases have a seasonal dependence. As will be shown, for spatial averages over the Asia land area, there is a tendency for seasonal temperature forecasts to have a negative bias during the fall and a positive bias during the spring, indicating a shifted GSM seasonal cycle. Biases can also have a geographic dependence. As will be shown, the western tier of China has a cold bias and the
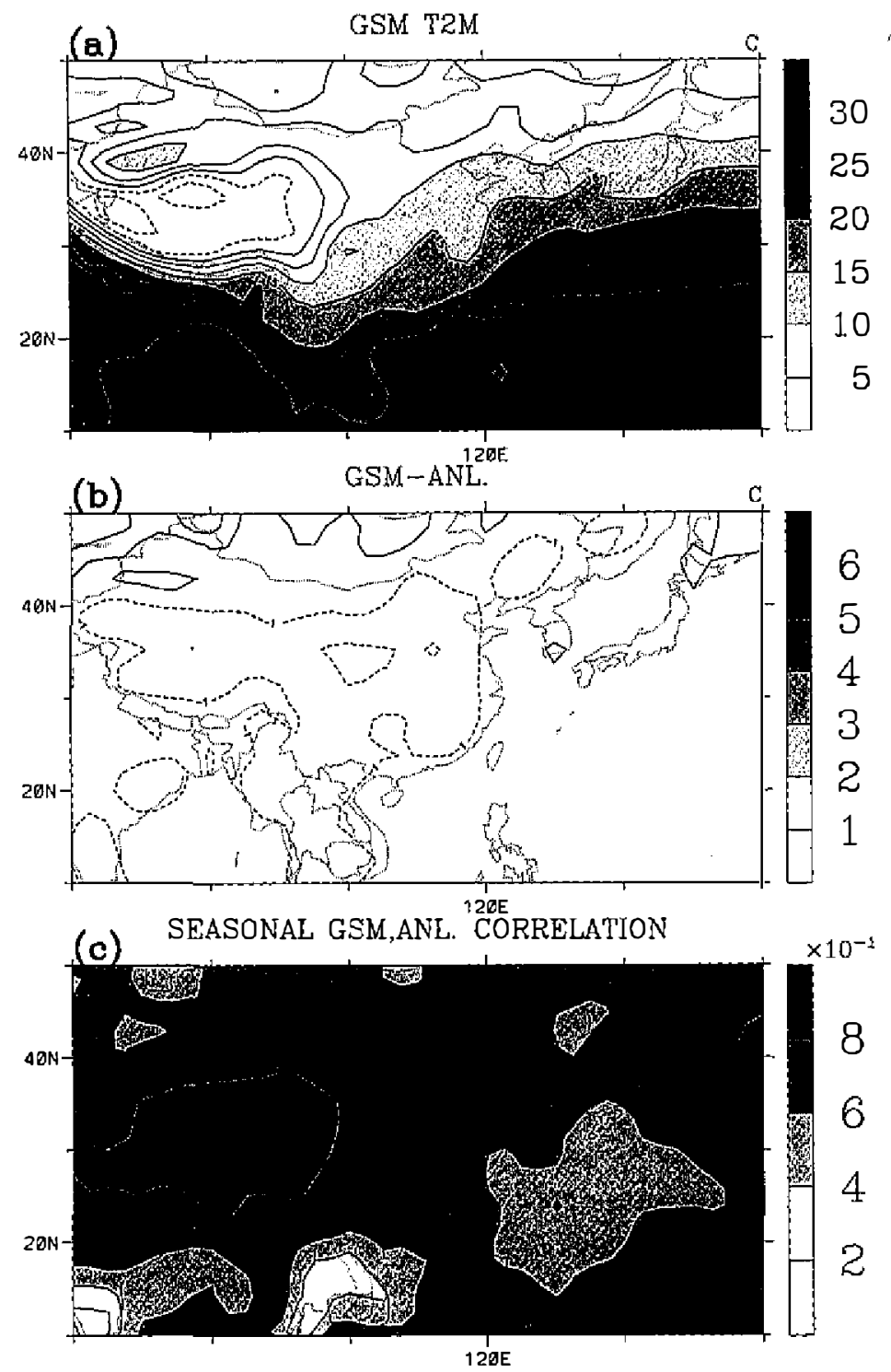

Fig. 1. 2-m Temperature seasonal predictions (97/10-99/10; 104 forecasts) over Asia: (a) GSM seasonal mean, ${ }^{\circ} \mathrm{C}$; (b) GSM - V1 analysis seasonal mean, ${ }^{\circ} \mathrm{C}$; (c) [GSM, Vl analysis] correlation. 
eastern tier has a warm bias. Also, biases depend upon forecast lag. Forecast biases for the 1st week are different from the forecast biases for the $12^{\text {th }}$ week. For example, initial GSM relative humidity is wet but by the $12^{\text {th }}$ week a dry bias develops.

Another skill evaluation is concerned with how well the model forecasts anomalies from the mean climatological state. It is usually quite difficult for dynamical models to exactly reproduce the mean state, even though they can still forecast the variations about the mean
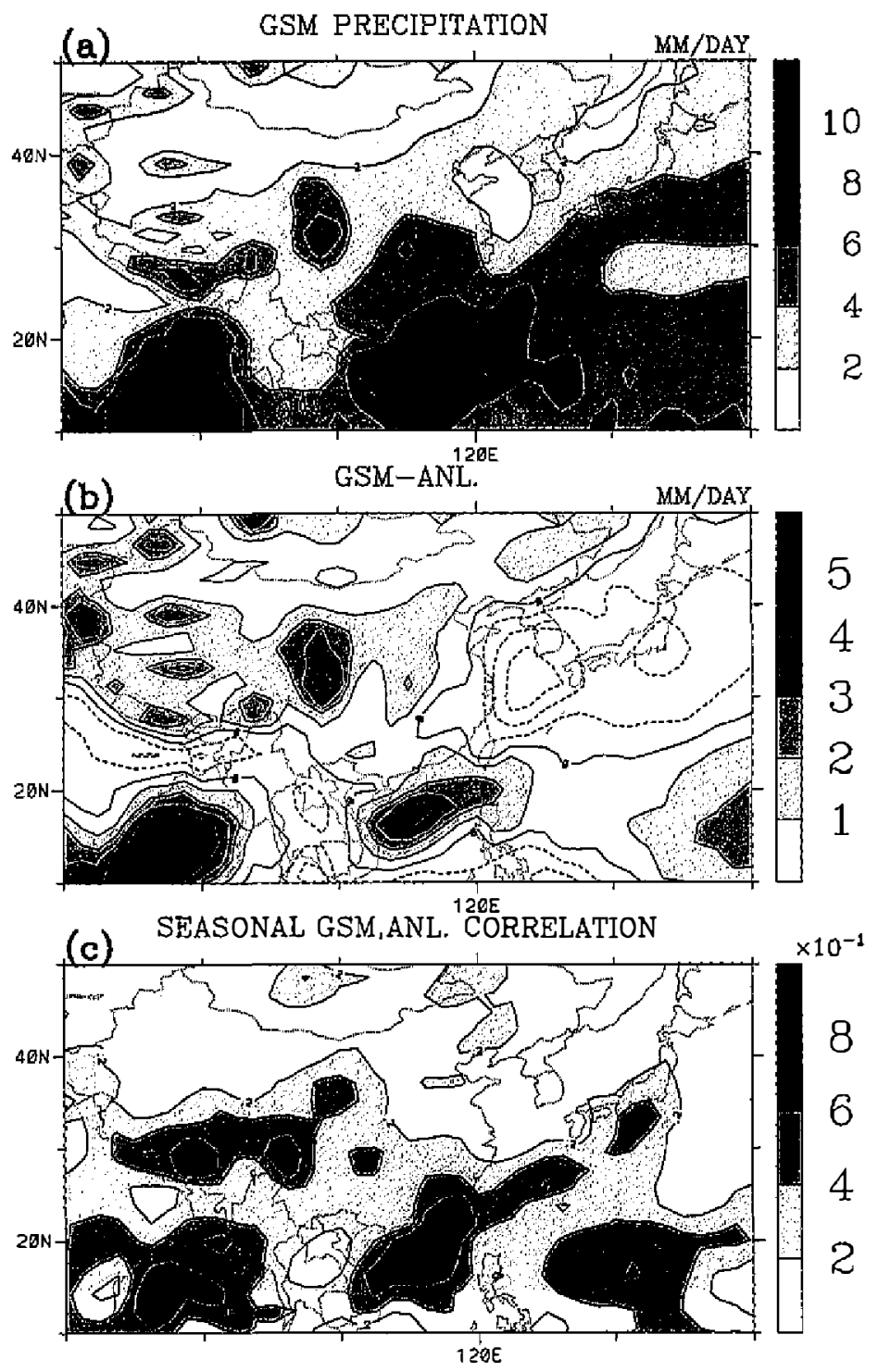

Fig. 2. Precipitation seasonal predictions (97/10-99/10; 104 forecasts) over Asia: (a) GSM seasonal mean, mm day ${ }^{-1}$; (b) GSM - VX analysis mean, mm day $^{-1}$; (c) [GSM, VX analysis] correlation. 
state. To evaluate the skill of these anomaly forecasts, we remove the associated (forecast or observed) climatological state for each grid point, for each initial state month, and for each forecast lag time. Averaging each monthly average with a 3-point Shapiro temporal filter removes noisy two-gridpoint temporal variations in the monthly climatologies. The anomalies are then defined separately for the forecast, $F$, and validating analysis, $O$ by:
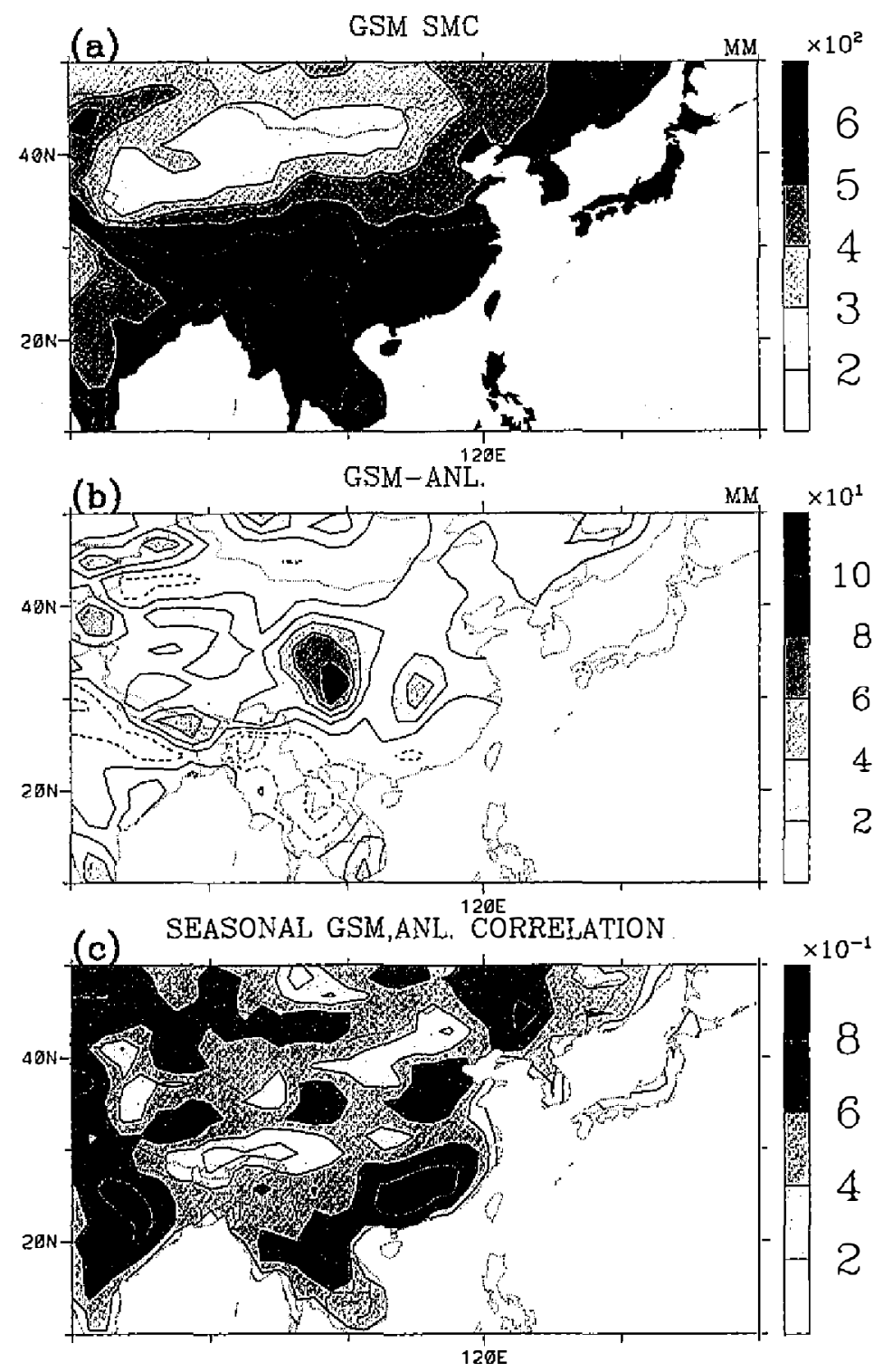

Fig. 3. Water content in 2-meter soil column seasonal predictions (97/10-99/10; 104 forecasts) over Asia: (a) GSM seasonal mean, mm; (b) GSM - V1 analysis mean, mm; (c) [GSM, V1 analysis] correlation. 


$$
F^{\prime}=F-[F] \text { and } O^{\prime}=O-[O],
$$

where $O^{\prime}$ is the observed (or analysis; note again that we are equating the analyses described above with observations; referring to the analysis as observation for some variables, like temperature, is probably adequate, but for other variables, like soil moisture, the analyses are probably inadequate) anomaly.
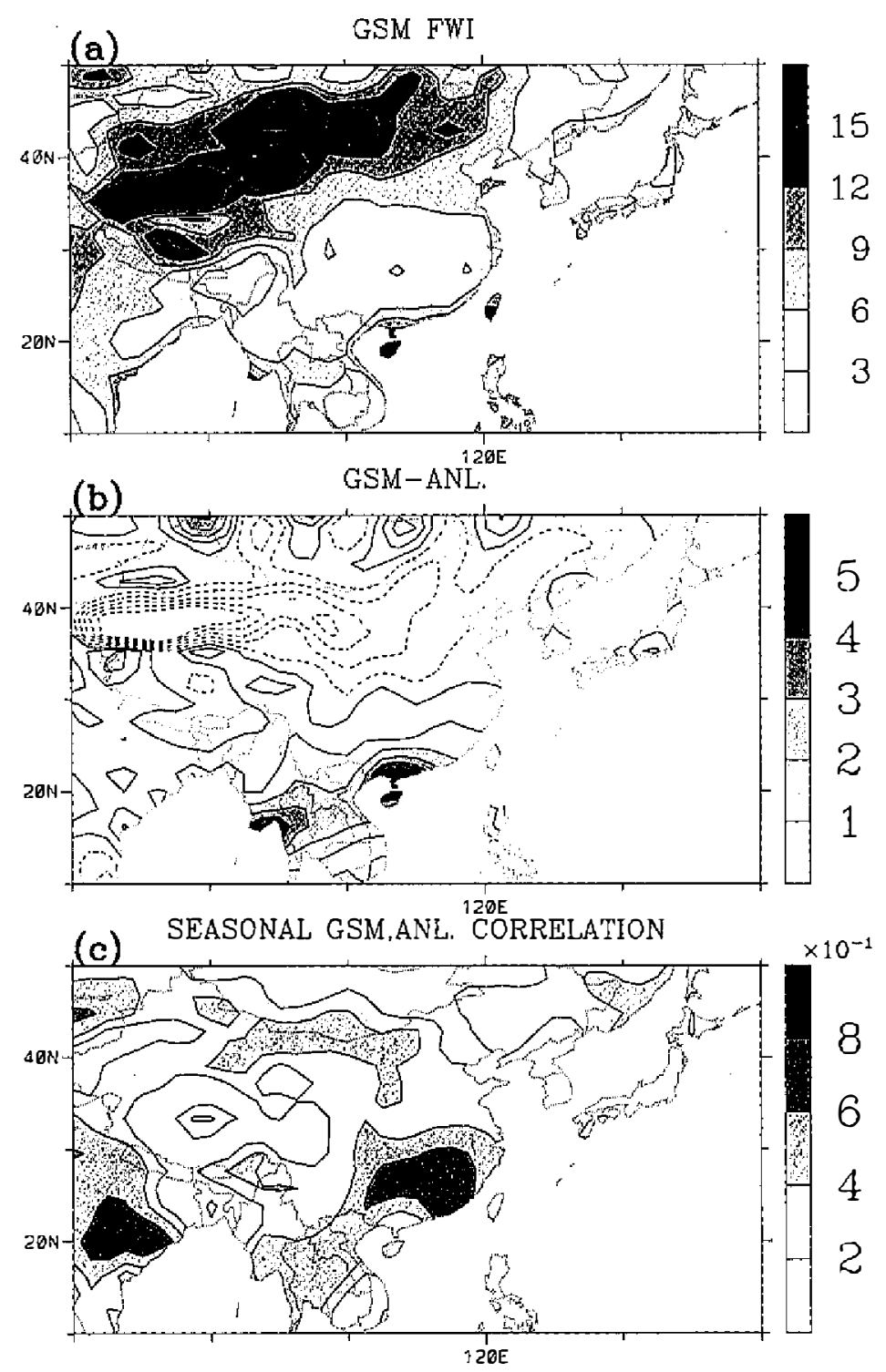

Fig. 4. FWI seasonal predictions (97/10-99/10; 104 forecasts) over Asia: (a) GSM seasonal mean; (b) GSM - VI analysis mean; (c) [GSM, V1 analysis] correlation. 
To evaluate skill significance, we now have correlations as normalized values as well as a body of standard literature about them

$$
[\operatorname{COR}(x)]=\frac{\left[F^{\prime} O^{\prime}\right]-\left[F^{\prime}\right]\left[O^{\prime}\right]}{\left(\left[F^{\prime 2}\right]-\left[F^{\prime}\right]^{2}\right)^{1 / 2}\left(\left[O^{\prime 2}\right]-\left[O^{\prime}\right]^{2}\right)^{1 / 2}} .
$$

This correlation can be calculated for each grid point to give spatial maps of the ensemble correlation for a complete annual cycle. For 104 (once a week from 10/97-10/99) independent forecasts, a correlation above 0.16 is considered significant at the $95 \%$ level (see Von Storch and Zwiers 1999). Assuming some degree of dependence between the weekly forecasts of seasonal means, we only plot correlations above 0.2 in the geographic maps (Figs. 1-4) of seasonal forecast mean correlation.

Correlations can also be calculated for various domain averages to provide an instantaneous average value, which can also be used to estimate how significant ensemble spatial averages are. In this case the time varying correlations consist of spatially weighted grid points for each forecast

$$
\{C O R(t)\}=\frac{\left\{F^{\prime} O^{\prime}\right\}-\left\{F^{\prime}\right\}\left\{O^{\prime}\right\}}{\left(\left\{F^{\prime 2}\right\}-\left\{F^{\prime}\right\}^{2}\right)^{1 / 2}\left(\left\{O^{\prime 2}\right\}-\left\{O^{\prime}\right\}^{2}\right)^{1 / 2}} .
$$

In particular, by calculating the temporal variations of spatially averaged correlations, one can estimate the standard deviations of the correlation for each collection of forecasts. That is, the standard deviation of the spatial correlations provides a measure of the climatological uncertainty for each forecast variable. This correlation can then be further transformed to a normal variable (see Roads 1989), although this makes only a small difference in practice.

Unfortunately, this measure of uncertainty breaks down for geographically small areas where the observed and forecast variations can be of one sign; that is, for small areas $\left\{F^{\prime}\right\}$ and $\left\{O^{\prime}\right\}$ can be nonzero instantaneously, even though $\left[\left\{F^{\prime}\right\}\right]$ and $\left[\left\{O^{\prime}\right\}\right]$ are zero. Although removing the spatial average presumably affects both the numerator and denominator, in practice it appears to reduce the numerator more. Thus $[\{\operatorname{COR}(t)\}]$ can be noticeably smaller than

$$
\frac{\left[\left\{F^{\prime} O^{\prime}\right\}\right]-\left[\left\{F^{\prime}\right\}\right]\left[\left\{O^{\prime}\right\}\right]}{\left(\left[\left\{F^{\prime 2}\right\}\right]-\left[\left\{F^{\prime}\right\}\right]^{2}\right)^{1 / 2}\left(\left[\left\{O^{\prime 2}\right\}\right]-\left[\left\{O^{\prime}\right\}\right]^{2}\right)^{1 / 2}}
$$

Because of this area mean problem in calculating instantaneous correlations for small areas, the normalized covariance was used to estimate the skill significance for individual times (see Figs. 5-8). That is

$$
\{\operatorname{COV}(t)\}=\frac{\left\{F^{\prime} O^{\prime}\right\}}{\left(\left\{F^{\prime 2}\right\}\right)^{1 / 2}\left(\left\{O^{\prime 2}\right\}\right)^{1 / 2}},
$$

and then because $\left[F^{\prime}\right]$ and $\left[O^{\prime}\right]$ are identically zero for the climatological mean

$$
[\{\operatorname{COV}\}] \cong \frac{\left[\left\{F^{\prime} O^{\prime}\right\}\right]-\left[\left\{F^{\prime}\right\}\right]\left[\left\{O^{\prime}\right\}\right]}{\left(\left[\left\{F^{\prime 2}\right\}\right]-\left[\left\{F^{\prime}\right\}\right]^{2}\right)^{1 / 2}\left(\left[\left\{O^{\prime 2}\right\}\right]-\left[\left\{O^{\prime}\right\}\right]^{2}\right)^{1 / 2}}
$$


Indeed, time (actually ensemble) averages of the temporally varying normalized covariance were much closer to time and space averaged correlations, which validates the use of instantaneous normalized covariance to estimate the significance of the ensemble correlations. It should be further noted, however, that it is mainly the time average that is affected by the choice of normalized covariance or correlation. Temporal variations in normalized covariance are actually quite comparable to temporal variations in correlation.

$\mathrm{T} 2$

(a) ASIA GSM ANL.

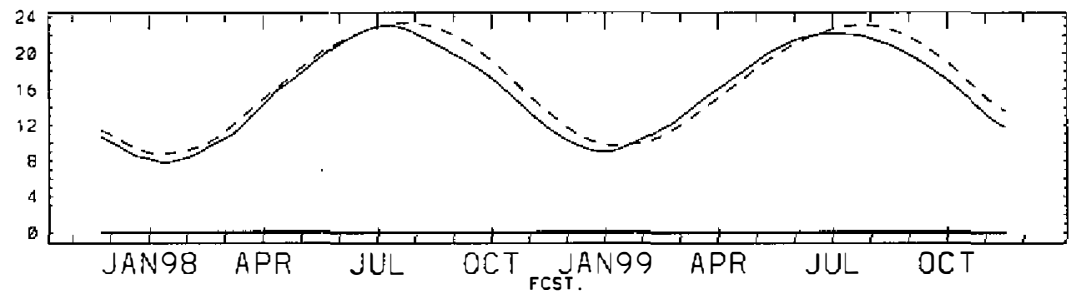

(b) ASIA GSM-ANL.

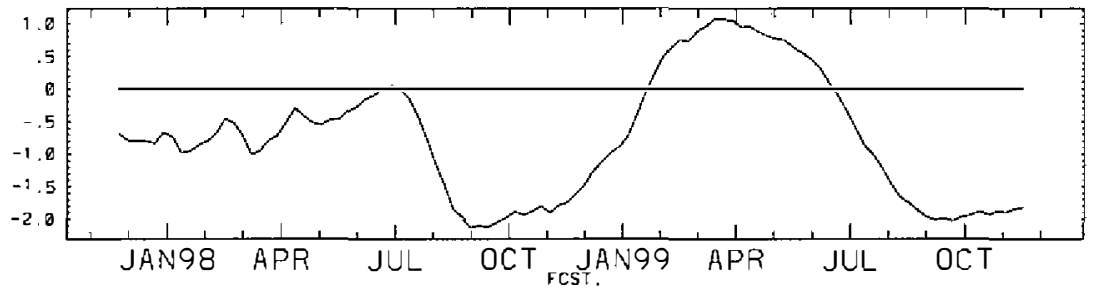

(c) ASIA GSM ANL. SD

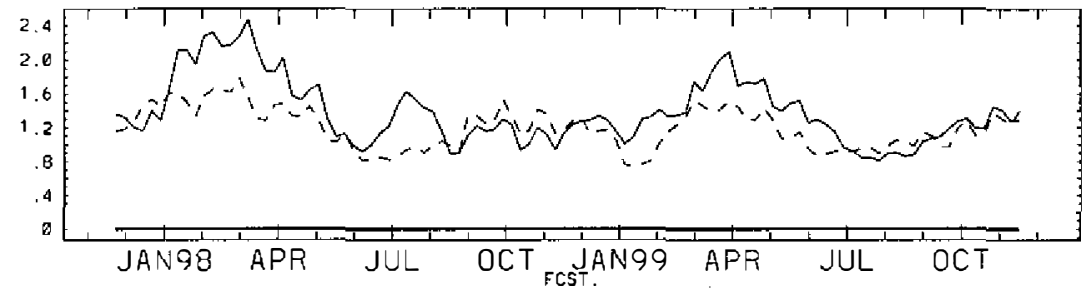

(d) ASIA \{GSM, ANL.\} COV.

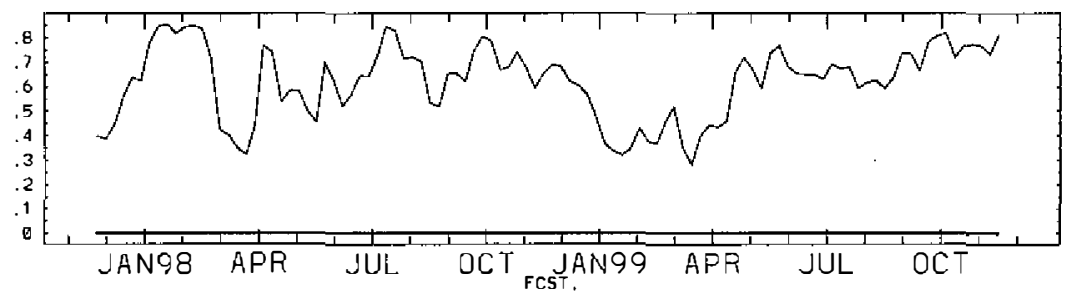

Fig. 5.2 m temperature seasonal forecast temporal variations (97/10-99/10; 104 forecasts; smoothed by 5 forecasts running mean) over Asia land region. (a) GSM (solid), V1 (dashed), ${ }^{\circ} \mathrm{C}$; (b) GSM - V1 (solid), ${ }^{\circ} \mathrm{C}$; (c) GSM (solid), V1 (dashed) RMS, ${ }^{\circ} \mathrm{C}$; (d) \{GSM, V1\} normalized seasonal covariance. 
Anyway, our measure of uncertainty here for an individual spatially averaged forecast will be two standard deviations of the normalized covariance, which is significant at the $95 \%$ level. That is

$$
V=2\left[\left(C O V-[C O V]^{2}\right]^{1 / 2} .\right.
$$

It should be further noted that the standard deviation, $\mathrm{U}$, for an ensemble of $\mathrm{N}$ independent forecasts is

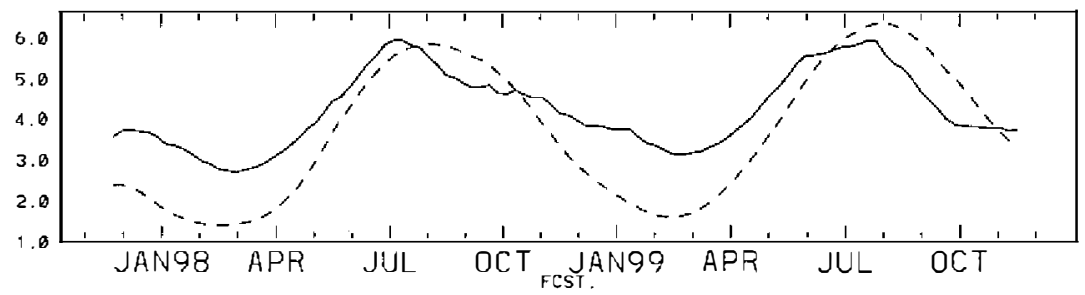

(b) ASIA GSM-ANL.

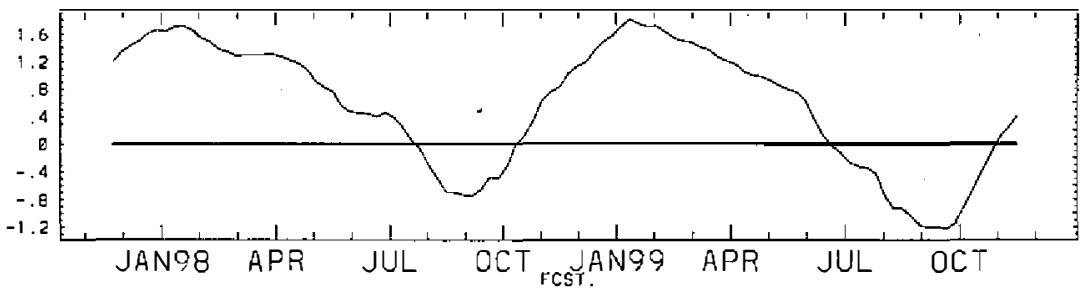

(c) ASIA GSM ANL. SD

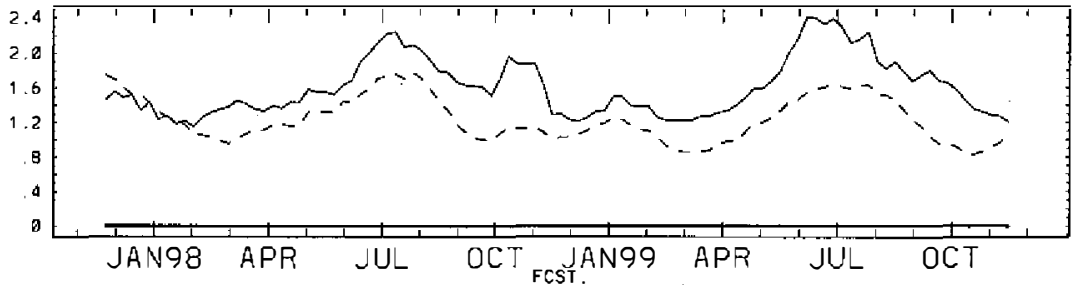

(d) ASIA \{GSM, ANL.\} COV.

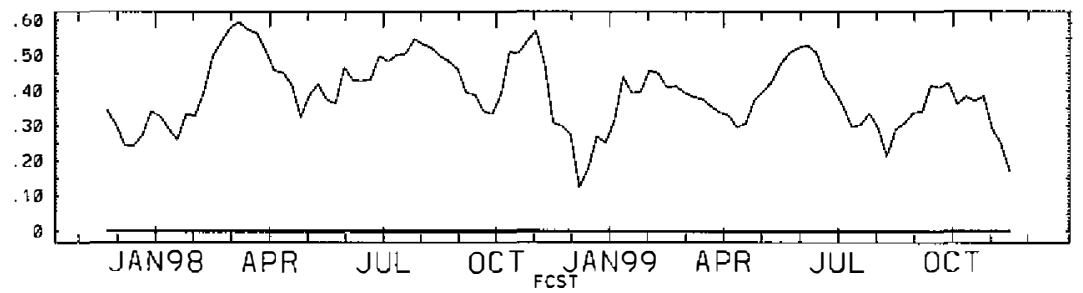

Fig. 6. Precipitation seasonal forecast temporal variations (97/10-99/10; 104 forecasts; smoothed by 5 forecasts running mean). (a) Global, GSM (solid), VX (dashed), mm day ${ }^{-1}$; (b) Global GSM - VX, mm day-1; (c) Global GSM (solid), VX (dashed) RMS, mm day ${ }^{1}$; (d) $\{$ GSM, VX\} normalized seasonal covariance. 


$$
\mathrm{U}=\mathrm{V} / \mathrm{N}^{1 / 2} \text {. }
$$

We assume this serial independence mainly for simplicity. In that regard it should be noted that the amount of serial dependence depends upon forecast variable as well as average, lag, etc.

In summary, to evaluate the significance of the spatially and temporally (ensemble) averaged forecasts, we assume that the skill is significantly different from zero if the correlation minus $\mathrm{U}$, which is an estimate of two standard deviations of the ensemble mean, is greater than

(a) ASIA GSM ANL.

SOIL MOISTURE

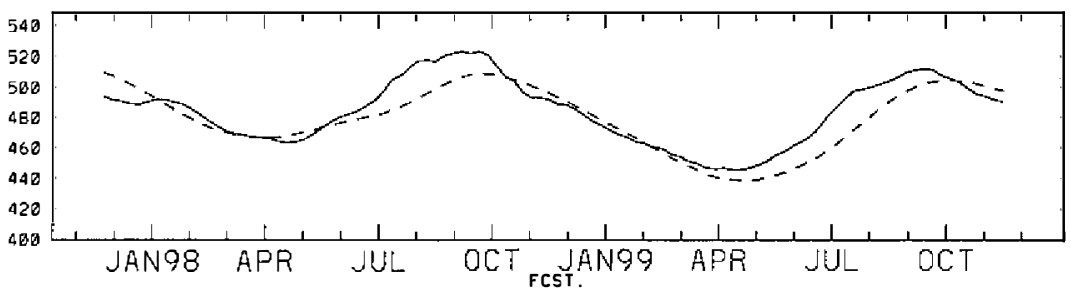

(b) ASIA GSM-ANL.

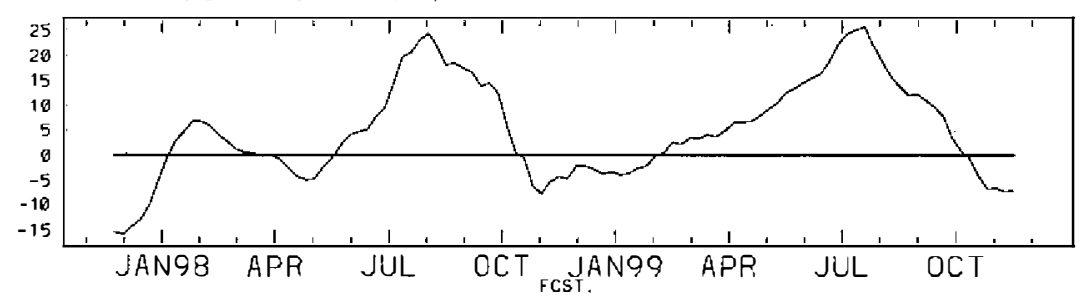

(c) ASIA GSM ANL. SD

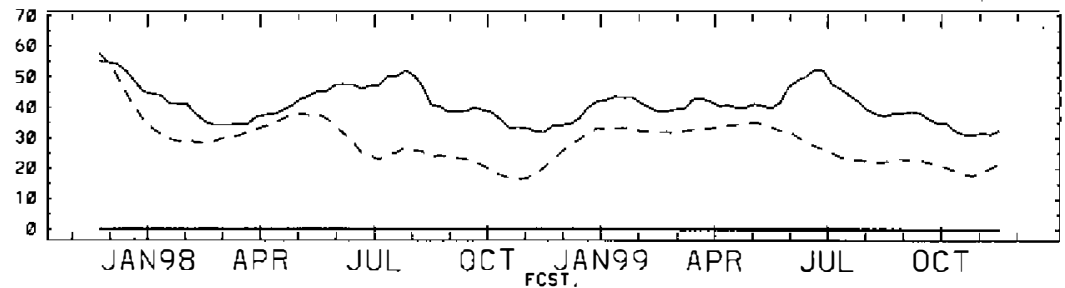

(d) ASIA (GSM, ANL.) COV.

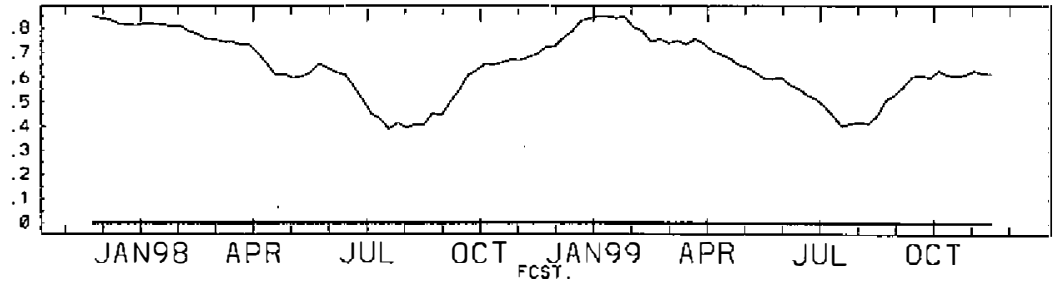

Fig. 7. Soil moisture seasonal forecast temporal variations (97/10-99/10; 104 forecasts; smoothed by 5 forecasts running mean. (a) GSM (solid), V1 (dashed), mm; (b) Global GSM - V1, mm; (c) Global GSM (solid), V1 (dashed) RMS, mm; (d) \{GSM, V1\} normalized seasonal covariance. 
zero. As will be shown, almost all forecasts are skillful, although some are more skillful than others.

\section{SPATIAL CHARACTERISTICS OF SEASONAL FORECASTS}

In this section we describe characteristics of the seasonal mean (12 week average) forecast fields and their biases and correlations with respect to V1 and VX over the Asia region.

\section{FWI}

(a) ASIA GSM ANL.

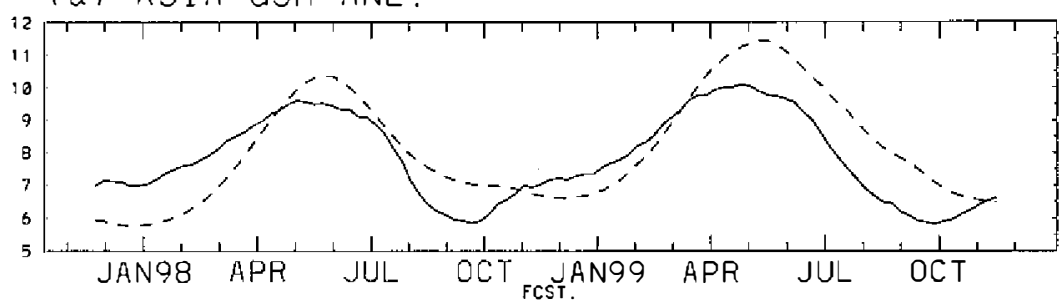

(b) ASIA GSM-ANL

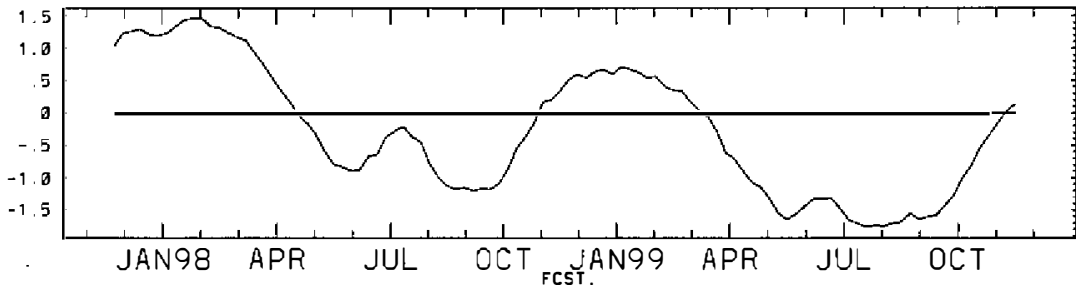

(c) ASIA GSM ANL. SD

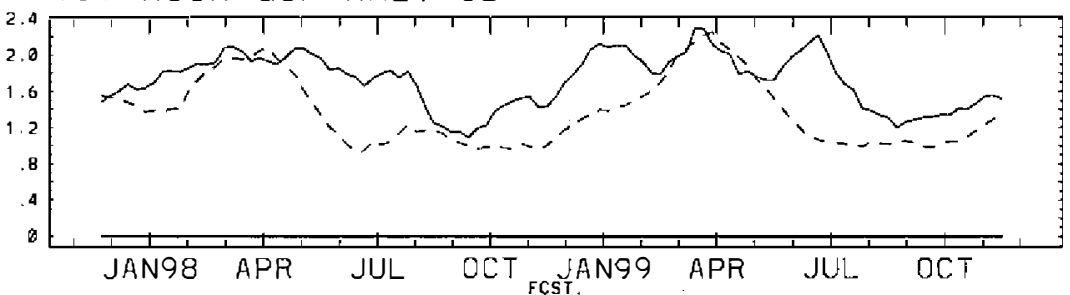

(d) ASIA (GSM, ANL. . COV

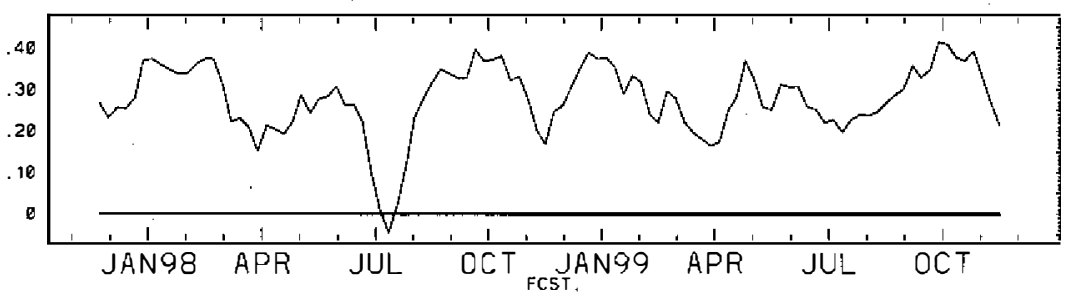

Fig. 8. FWI seasonal forecast temporal variations (97/10-99/10; 104 forecasts; smoothed by 5 forecasts running mean). (a) GSM (solid), V1 (dashed); (b) Global GSM - V1; (c) Global GSM (solid), V1 (dashed) RMS; (d) $\{G S M, V 1\}$ normalized seasonal covariance. 
We examined 6 near surface variables; 2 -m temperature, 2-m relative humidity, 10-m wind speed, soil moisture, precipitation, and a fire weather index. The basis for the fire weather index, a useful index in fire-preventing management, was described by Roads et al. (1991, 2000a). Suffice it to say that the fire weather index (FWI) represents a simplified index for fire potential that has proven useful in several cases, especially for global forecasts. The skill of these forecasts will be discussed below after we first discuss the skill of the basic meteorological variables.

As shown in Fig. 1a, GSM seasonal forecasts for the daily averaged 2-meter surface temperature provide typical $2 \mathrm{~m}$-temperature field, high in the tropics and decreasing toward high latitudes and elevations. Figure $1 \mathrm{~b}$ shows there is a tendency for the forecasts to have a small cold bias over most of the land region. The bias is generally small. The correlation of seasonal mean forecasts, Fig. $1 \mathrm{c}$ is high just about everywhere. The highest skill is found over the Tibetan plateau as well as most of the land regions. Regions with relatively low skill appear over the Indo-China monsoon area and the northwestern subtropical region. The low skill is probably due to the use of persistent SSTA over a region with highly variable SST. Since variable SSTA invalidates our use of persistent SSTA, it would be of interest eventually to compare these forecasts with forecasts using observed and climatological SSTAs in order to understand current and possible future (coupled ocean-atmosphere) temperature prediction capabilities.

GSM seasonal forecasts of precipitation have a characteristic monsoon precipitation over the Indian Ocean and South China Sea (Fig. 2a). These climatological maximum precipitation areas also have considerable bias (presumably due to the defects of the model precipitation schemes, see Kalnay et al. 1996) with respect to the VX validating analysis (Fig. 2b). Seasonal precipitation forecasts diminish in amplitude over the East China Sea, while monsoon oceans have a wet bias, as do inland Asia regions. The seasonal mean forecast correlations are statistically significant in several regions; mainly those associated with the Indian and East Asia monsoon phenomenon (Fig. 2c) in the Pacific and Indian Ocean, indicating that the variations are fairly well predicted despite noticeable bias. The skillful forecasts in these regions might be very well attributed to the strong influences (e.g., Lau and Wu 1999) of the slowly varying tropical SST which we persist the initial anomaly. It should be noted again, however, that the bias is taken into account before evaluating the correlation. That is, as discussed previously, each forecast lead has an associated (monthly and forecast lead-time) climatology removed before evaluating the correlation.

The least skillful seasonal forecasts occur over storm-rrack region north of $35 \mathrm{~N}$ near the East China coastal area where the dry bias occurs. This is presumably a defect of underestimated cyclogenesis in the model. Since the soil moisture is well predicted over this area (and will be shown later), we again suspect that the assumed non-interactive SSTA over the East China Sea may partially explain the low forecast skill in this region.

The GSM seasonal forecast soil moisture in Fig. 3a (total water content in 2-meter column of soil) demonstrates low values over the Gobi desert where precipitation in Fig. 2a is also low. Higher values occur for Southeast China and Indo-China. Figure $3 b$ shows the biases of seasonal forecast climatology with respect to the validating analysis. The bias is noticeable and is related to the biases in the forecast precipitation field. For example, the high bias over 
central China and low bias over Indo-China peninsula. Again, the bias can be removed and the seasonal forecasts show considerable skill (Fig. 3c), comparable to the skill previously shown for the temperature field. The correlations are fairly high about everywhere, ranging from .6 to .8. As shall be shown, later, all of this forecast skill is presumably related to the low frequency variability of this field. In that regard it appears to be more important to obtain an accurate soil moisture analysis for initializing the model than it is to make the actual forecast.

As shown in Fig. 4a, the GSM seasonal forecast fire weather index (FWI), which basically reflects wind speed and relative humidity, is the inverse of the relative humidity and soil moisture. It is relatively high in those regions of low soil moisture (Fig. 3a) and relative humidity (not shown but very similar to Fig. 3a). Although variations in the FWI are also reflected by the wind speed, it does not include vegetation stress, which must somehow be related to soil moisture, and which is better incorporated in standard fire danger indices (See Roads et al. 2000a). As shown in Fig. 4b, there is a tendency for the forecasts to have a negative bias in the northern Asia and positive bias over southeastern Asia. Not shown in this paper for the sake of brevity, but this dipole pattern can be traced to the tendency for the model to have relatively high (low) relative humidity and a negative (positive) wind bias over the low (high) FWI biases. Still, seasonal forecast correlations (Figs. 4) are high over much of the Asia, except for the Tibetan Plateau. The correlation pattern resembles more the relative humidity correlation pattern (not shown) (instead of the wind speed correlation pattern), indicating that it is the relatively accurate forecasts of relative humidity, more than windspeed, that provide some skill for the forecast FWI at long (seasonal) time scales.

\section{TEMPORAL CHARACTERISTICS OF SEASONAL FORECASTS}

Temporal characteristics of temperature variations over the Asia land region with respect to validating analysis, V1, are shown in Fig. 5. The seasonal forecast temperature fields are quite consistent with the validating analysis, which is shown in Fig. 5a. In comparison to the strong seasonal variations, differences between the validating analysis and forecasts are very small. The differences only show up in the biases (Fig. 5b), which indicates a tendency for the seasonal forecast to have a distinct maximum cold bias during the early fall and a maximum warm bias during the spring. Similar features occur for the global means as well as over U.S. (Roads et al., 2000). Figure 5c shows that the seasonal forecast spatial variances are slightly larger than the analysis (V1) variations, but still faithfully represent the intraseasonal variations. This quantity is calculated as the root-mean-squared (RMS) of the respective seasonal forecast and analysis. Figure $5 \mathrm{~d}$ shows the temporal variations of the normalized covariance between forecasts and validating analysis. Consistent with the spatial covariance in Fig. 1c, the skill is quite high throughout the entire experiment period, except during the seasonal transition in March and April. Note that the skills have fairly strong temporal variations but do not demonstrate any significant seasonal variations. However, it seems that this intraseasonal variation was much weaker after the La Nina began. Relative humidity (not shown) also has a very similar temporal variation as the 2-meter temperature. The reasons for the variation contrast in skill are currently unknown, but may be related to intraseasonal variations in the tropical region (see Chen et al. 1993). 
Temporal characteristics of Asia region precipitation variations with respect to validating analysis, VX, are shown in Fig. 6. Note that the seasonal forecast precipitation fields show strong biases with the VX validating analysis (Fig. 6a). As seen in Fig. 6b, the model bias, with respect to VX, has a strong seasonal cycle. A large wet bias occurs during mid-winter and dry bias occurs in the fall, which in effect is a decreased precipitation annual cycle. By contrast, the maximum wet bias over the U.S. land region occurs during May-June (see RCF), which results in an enhanced annual cycle there. Biases can have complicated seasonal and regional variations. Despite this strong bias, the spatial variations in the seasonal forecast are comparable to the analysis variations (Fig. 6c). Generally, large climatological precipitation corresponds to larger spatial variance. Unlike the bias, Fig. 6d shows that skill has no seasonal or inter-annual pattern. In contrast to the strong seasonal pattern in skill over U.S. land region (RCF), the skill over the land regions of Asia have an even more significant skill 0.35 (99\%) level, with the possible exception of the winter of 1998-99.

As discussed earlier, soil moisture is the most skillfully predicted variable in the model due to its slowly varying characteristics. Temporal characteristics of soil moisture variations, with respect to the validating analysis, are shown in Fig. 7. The model reproduces the strong annual cycle in the analysis as in Fig. 7a. The bias (Fig. 7b) is relatively small in comparison to its total value. Figs. 7c shows that the analysis and forecast GSM variations are comparable albeit somewhat higher in the forecasts, like all the other forecast fields. Figs. 7d show that skill, as measured by normalized covariance has a seasonal pattern, with the highest skill occurring during the wintertime. Although the soil moisture may have a noticeable impact on the near surface temperature over the U.S. (e.g., Huang and van den Dool 1993), temporal variations of 2 meter temperature skill (Fig. 5d) show little relevance to soil moisture skill in this region.

Figure 8 shows temporal characteristics of FWI variations. Like the soil moisture, there is a distinct annual cycle with lower FWI during the first early fall and higher FWI during late spring (Fig. 8a). However there is also a noticeable bias in the FWI (Fig. 8b), which is due mainly to the bias in the relative humidity (not shown). The model's relatively weak wind speed in this area also contributes to this bias. Again, the forecast model standard deviations are somewhat stronger than the analysis standard deviations (Fig. 8c). The normalized covariance skill is statistically significant and shows little seasonal variation (Fig. 8d) but strong intraseasonal variation.

\section{ENSEMBLE SKILL AND SYSTEMATIC BIAS OF WEEKLY TO SEASONAL FORECASTS}

Figure 9 shows the average skill as measured by spatially averaged correlations for weekly GSM forecasts (thin solid lines) versus weekly persistence forecasts using V1 (VX for precipitation) (thin dashed line). Error bars (+-U) indicate an estimate for 2 standard deviations for the average forecast skill. Again, these estimates are made by calculating the standard deviations of the normalized covariance of individual forecasts (the normalized seasonal covariance were shown previously in Figs. 5-8). Also shown are monthly forecast ("O") and 


\section{ASIA}

(a) PREC. GSM ANL. CORR.

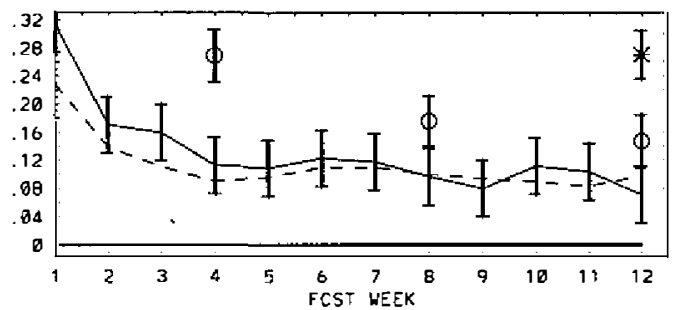

(c) R2 GSM ANL. CORR.

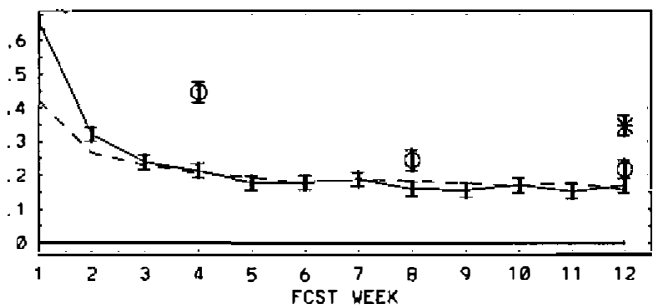

(e) SMC GSM ANL. CORR.

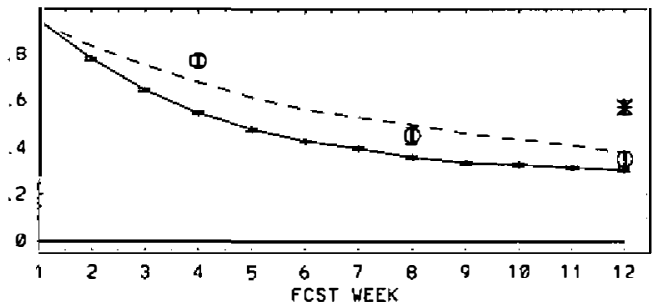

(b) T2 GSM ANL. CORR.

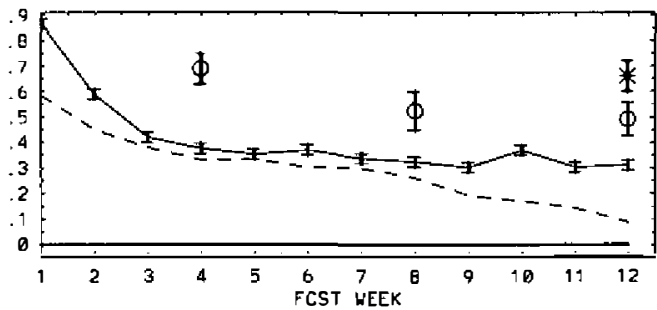

(d) WSP GSM ANL. CORR.

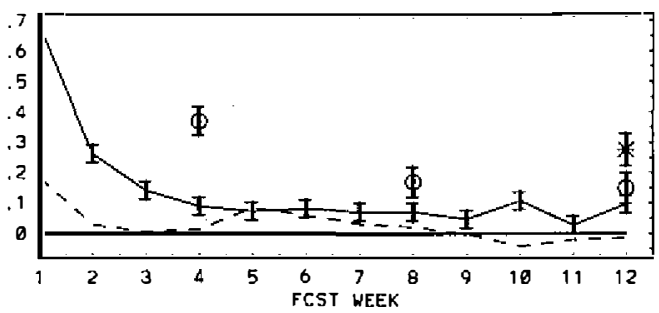

(f) FWI GSM ANL. CORR.

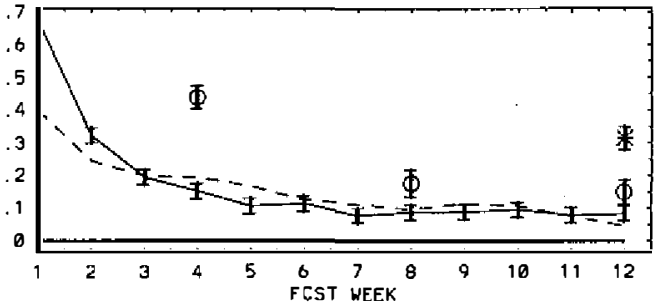

Fig. 9. Ensemble correlations \{GSM, analysis\} for weekly GSM forecasts (solid) versus persistence forecasts (dashed). Correlations \{GSM, analysis\} for monthly means ("o") and seasonal means ("*") are also shown. VX is used for precipitation, and V1 is used for all other variables. Estimates of the time-average forecast variations (discussed in the text) are shown by the error bars for the weekly, monthly and seasonal (GSM, analysis) means. (a) Precipitation; (b) $2 \mathrm{~m}$ temperature; (c) relative humidity; (d) wind speed; (e) soil moisture; (f) FWI.

seasonal forecast skills ("*") along with their respective monthly and seasonal error bars.

There is skill at weekly to seasonal time scales that is larger for the forecast model than persistent forecasts for temperature and wind-speed. For these two variables, the skill is significant for up to 12 weeks. For all variables, except soil moisture, the skill is higher when 4week averages (monthly means) or 12-week averages (seasonal means) are used. This is shown by skill greater than the persistent forecast uncertainty represented by the error bars. Presumably this time average skill arises because of the persistent boundary conditions. The skill is especially high for the surface temperature (Fig. 9b) and soil moisture. Not surprisingly, precipitation (Fig. 9a) appears to be the most difficult variable to forecast. Wind-speed (Fig. 9d) 
ASIA
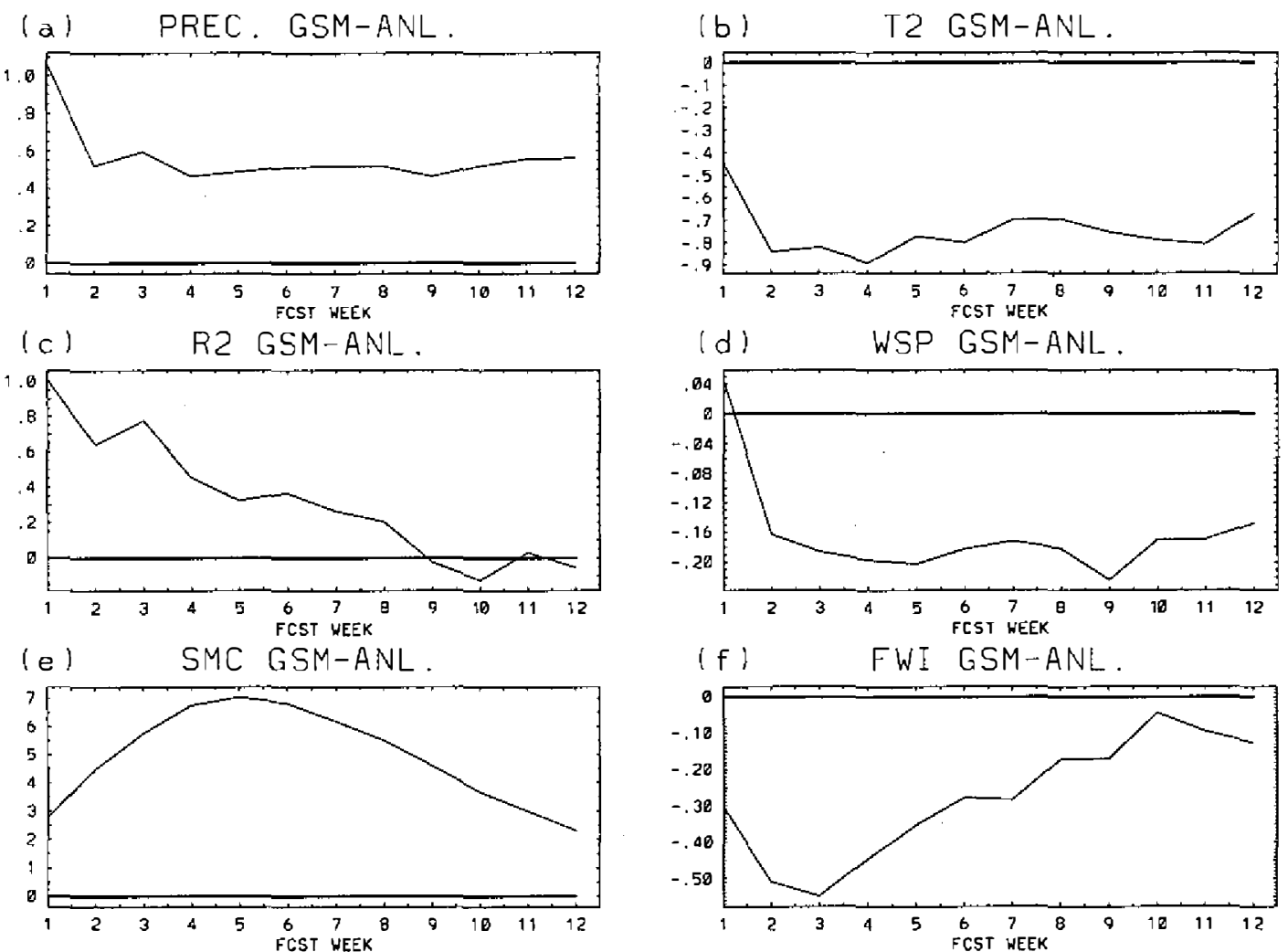

Fig. 10. Average forecast biases \{GSM-analysis \} for weekly GSM forecasts. (a) Precipitation; (b) 2 m temperature; (c) relative humidity; (d) wind speed; (e) soil moisture; (f) FWI. VX is used for precipitation, and V1 is used for all other variables.

is also difficult but the skill is statistically better than the persistent forecast. Relative humidity forecasts (Fig. 9c) show relatively high skill, although given the strong influence of temperature on relative humidity, this should perhaps not be too surprising. Fortunately the FWI (Fig. 9f) depends more upon relative humidity than wind speed and reveals similar skill characteristic. For all variables, regional skill is higher than the global skill (not shown). There are likely various reasons for this increased regional skill, including potential intrinsic skill. However, because of the smaller domain, and the less number of independent grid points, variations in individual regional forecasts (error bars) are much larger and the significance of the skill is therefore lower.

Due to its slowly varying characteristics, it is not surprising to see that the model soil moisture provides almost identical skill as persistence at the $1^{\text {st }}$ week. However at longer range, similar but still somewhat lower skill than the persisted soil moisture anomaly is found. Since the V1 soil moisture analysis is presumably very similar to the GDAS, which is subject to the 
non-stationary changes in NCEP's operational analysis scheme during these two years period, our frozen version of the forecasting model might have an inconsistent temporal variation compared with the analysis. Another possible reason is that the soil moisture in the model accumulates all precipitation and evaporation errors as the forecast progresses. This is a problem which is not too dissimilar to what has been found in efforts to forecast midlatitude sea surface temperature (see Miller and Roads 1990). That is, atmosphere-ocean coupled models have so far only succeeded in making better predictions in the ropics. Globally, SST and soil moisture are still predicted better by using persistence. Again, it is this persistence that presumably helps to provide the forecast skill demonstrated in other variables. In that regard, it should be noted that the fire danger index includes a number of vegetation characteristics that presumably act like soil moisture. Thus fire danger has an unrealized potential long range forecast capability that may be achieved in part by the slowly varying initial vegetation state as well as the faster varying and more difficult to predict windspeed and relative humidity.

Perhaps as a result of slowly varying boundary conditions, all variables, except for soil moisture, show a positive influence of time averaging, indicating that forecasts of time averages show improved skill. These increased time average skills can still be identified, even over lags of 2 months. Note that at 2 months lag the influence of the high skill at the first few days of forecast is not accounted for. In the previous experiments discussed by Roads (1989) and Chen et al. (1993), time averaging did not have a strong impact, presumably because the forecast time (up to a month) was too short to be influenced by slowly varying boundary conditions. Now that we have the capability to make longer forecasts, time averaging does seem to help. Note that seasonal forecast skill at zero lag is also almost as good as forecasts of one month at zero lag, indicating the usefulness of dynamical models (in a time averaged sense) at this time range.

Figure 10 shows the average biases over Asia (land only) that develop during the forecasts. Apparently there is a significant amount of precipitation spin-down after the initial spin-up during the first week of forecasts (Fig. 10a). Temperature (Fig. 10b) has a cold bias, with a similar quick adjustment during the second week as in precipitation. Relative humidity has a small positive bias almost throughout the entire lags (Fig. 10c). Wind speed shows an initial small positive and then a negative bias (Fig. 10d). Soil moisture seems to have a longer adjusting time scale than other variables. The positive bias increases to the maximum value at $5^{\text {th }}$ week, then decreasing to its initial level, unlike the continuing drying trend over U.S. land region (Roads et al. 2000). We believe that this decrease is not finished at the end of the $12^{\text {th }}$ week (Fig. 10e), and the trend will continue to a slightly negative bias as GSM experiment suggested in Roads et al. (1999). Because of the positive relative humidity and negative windspeed biases, the FWI is too weak initially, but then approaches to zero bias as forecast times increase (Fig. 10f). This change mimics the relative humidity variations, although clearly the wind speed bias is also important, indicated from the first few weeks of forecasts. Noticeable differences in bias can be seen when comparing Fig. 10 to that in Roads et al. (2000) over U. S. land region, especially for relative humidity, soil moisture and FWI. The causes of these regional dependent biases are rather complicated and currently unknown. However it is important to recognize the inherent biases in the forecasts, for each geographic region, for each season (not shown), and for each time lag. However, it should also be recognized that, despite 
these biases, skillful seasonal predictions of the anomalous variations can still be made so long as proper accounting for the biases are made.

\section{SUMMARY AND DISCUSSION}

The Scripps Experimental Climate Prediction Center (ECPC) has been making experimental, near real-time global forecasts since Sept. 26, 1997. The global forecast model is based upon the National Centers for Environmental Prediction's (NCEP's) global spectral model (GSM; Kalnay et al. 1996). The initial conditions and SST boundary conditions come from the NCEP operational global analysis at 0 UTC. 7-day forecasts are made every day, and every weekend these forecasts are extended to 12 weeks. Although the SST climatology varies throughout the forecast, the initial SST climatic anomaly is artificially persisted throughout the forecast. Over 104 12-week forecasts have now been made (a 12 week forecast is made once a week; on Sept. 23, 2000 we will have 156 forecasts). The purpose of this paper has been to describe the forecast system as well as the various biases and errors over the regions of Asia, including the western Pacific, in order to augment RCF's United States focus. In brief, many relevant near-surface meteorological parameters (including temperature, precipitation, soil moisture, relative humidity, wind speed, and a fire weather index, which is a nonlinear combination of weather variables) are reasonably skillful at weekly to seasonal time scales over much of the Asia region.

Surface temperature forecasts are the most skillful, with seasonal forecast correlations of .7. Not surprisingly, precipitation has much lower forecast skill of 0.3 . Relative humidity is a bit more skillful at seasonal time scales with correlations at 0.35 . Wind-speed forecasts are more problematic with seasonal forecast skill at 0.28 . FWI, which is a nonlinear combination of windspeed and relative humidity, has a somewhat higher forecast skill, which presumably arises from the contribution of the relative humidity to the FWI. Finally, soil moisture forecasts are skillful but show little skill beyond what is available from simply persisting the initial state. Nonetheless, the strong persistence of the soil moisture is presumably one of the controlling features on the ability of the model to make skillful seasonal forecasts of temperature and other variables. It should in fact be noted that for all other variables, the model forecast skill is generally greater than persistence. It should also be noted that forecast skill almost always increases with averaging length. This is due in part to the inclusion of skillful initial forecasts, however, additional skill does seem to occur and even monthly forecasts with two-month lags are more skillful than corresponding weekly forecasts with similar lags.

Even better weekly to seasonal forecasts can probably be made. Now that we have examined the forecast skill of this model with persistent SST anomaly, we intend to conduct hindcast experiments with specified observed SST. The peculiar high bias and low skill regions over eastern China and Eastern China Sea will be the focus of these additional experiments. We will also upgrade the model to the latest operational model and repeat the comparisons. A number of noticeable improvements have been made since this model was frozen for the reanalysis and were incorporated in the NCEP reanalysis II model (see Kanamitsu et al. 1998). Many regional extensions to ECPC's experimental global forecast system are also under development. In particular, the GSM currently forces a regional spectral model (RSM; Juang 
and Kanamitsu 1994; Juang et al. 1997) in order to gain increased spatial resolution (50-15 km resolution) for shorter time scales (4xdaily- 4-weeks) for several limited regions. (See also Chen et al. 1999; Roads et al. 2000). An effort is underway to produce and evaluate regional forecasts over the Taiwan area at $15-\mathrm{km}$ resolution. Regional extensions and hydrological applications of the global and regional forecasts will be discussed in future papers.

Acknowledgements This research was funded by a cooperative agreement from NOAANA77RJ0453, NASA NAG54775, NSC-88-2621-Z002-024, and NSC-89-2119-M-002-003. The views expressed herein are those of the authors and do not necessarily reflect the views of NOAA, NAȘA and NSC. Jack Ritchie has performed the Herculean task of maintaining this quasi-operational system since 1998. We are also grateful to M. Kanamitsu and H. Juang of NCEP for providing us with the model as well as many useful answers to many questions. Finally, we are in debt to three reviewers who offered valuable comments and suggestions.

\section{REFERENCES}

Ai, Y., and G. Chen, 1998: Evaluation of long-range flood prediction schemes. Review of Climate Prediction, National Climate Center, 1998, 166-170 (in Chinese).

Anderson, B. T., J. Roads, S. Chen, and H.-M. Juang, 2000: Regional modeling of the lowlevel monsoon winds over the Gulf of Califomia and Southwest United States: Simulation and validation. J. Geophys. Res. Atmos., 105, D14, 17955-17969.

Barnston, A., 1994: Linear statistical short-term climate predictive skill in the Northern Hemisphere. J. Climate, 7, 1513-1564.

Barnston, A.G., and T.M. Smith, 1996: Specification and prediction of global surface temperature and precipitatin from global SST using CCA. J. Climate, 9, 2660-2697.

Brankovic C, T.N. Palmer, and L.Ferranti, 1994: Predictability of seasonal atmospheric variations. J. Climate, 7(2), 217-237.

Caplan, P. J. Derber, W. Gemmil, S.-Y. Hong, H.-L. Pan, and D. Parrish, 1997: Changes to the 1995 NCEP operation medium-range forecast model analysis-forecast system. Weather Forecast., 12, 581-594.

Chen, S.-C., J.O. Roads, and J.C. Alpert, 1993: Variability and predictability in an empirically forced global model. J. Atmos. Sci., 50, 443-463.

Chen, S.-C., J. Roads, H.-M. H. Juang, M. Kanamitsu, 1999: Global to regional simulation of California's wintertime precipitation. J. Geophys. Res., 104(ND24), 31517-31532.

Chu, P.-S., 1998: Short-term climate prediction of Mei-Yu rainfall for Taiwan using canonical correlation analysis. J. Climat. 18, 215-224.

Hong, S. Y., and A. Leetmaa, 1999: An Evaluation of the NCEP RSM for regional climate modeling. J. Climate, 12(N2), 592-609.

Huang, J., and H. M. van den Dool, 1993: Monthly precipitation-temperature relations and temperature prediction over the U.S. J. Climate, 6, 111-1132.

Juang, H. -M. H., and M. Kanamitsu, 1994: The NMC nested regional spectral model. Mon. Wea. Rev., 122, 3-26. 
Juang, H.-M. H., S.-Y. Hong, and M. Kanamitsu, 1997: The NCEP regional spectral model: an update. Bull. Amer. Meteor. Soc., 78, 2125-2143.

Kalnay, E., M. Kanamitsu, R. Kistler, W. Collins, D. Deaven, L. Gandin, M. Iredell, S. Saha, G. White, J. Woolen, Y. Zhu, A. Leetma, R. Reynolds, M. Chelliah, W. Ebisuzaki, W. Higgins, J. Janowiak, K.C. Mo, R. Jenne, and D. Joseph, 1996: The NCEP/NCAR 40year reanalysis project. Bull. Amer. Meteor. Soc., 77, 437-471.

Kanamitsu, M., 1989: Description of the NMC global data assimilation and forecast system. Wea. Forecasting, 4, 335-342.

Kanamitsu, M., W. Ebisuzaki, J. Woolen, J. Potter, and M. Fiorino, 1998: An overview of NCEP/Doe reanalysis-2, paper presented at Climate Diagnostics Workshop, Miami, Florida, October 26-30.

Kumar, A., and M. Hoerling, 1998: Annual cycle of Pacific-north American seasonal predictability associated with different phases of ENSO. J. Climate, 11, 3295-3308.

Lau, K. M., and H.-T. Wu, 1999: Assessment of the impacts of the 1997-98 El Nino on the Asian-Australia monsoon. Geophys. Res. Letters, 26, 1747-1750.

Lorenz, E., 1965: A study of the predictability of a 28-variable atmospheric model. Tellus, 17, 321-333.

Lorenz, E., 1982: Amospheric predictability experiments with a large numerical model. Tellus, 34, 505-513.

Miller, A. J., and J. Roads, 1990: A simplified coupled model of extended range predictability, J. Climate, 3, 523-542.

Roads, J., 1989: Dynamical extended range forecasts of the lower tropospheric thickness. Mon. Wea. Rev., 117, 3-28.

Roads, J., K. Ueyoshi, S. Chen, J. Alpert, and F. Fujioka, 1991: Medium-range fire weather forecasts. Intern. J. Wildland Fire, 1, 159-176.

Roads, J., S.-C. Chen, F. M. Fujioka, H. Juang, and M. Kanamitsu. 1997. Global to regional fire weather forecasts. Int. Forest Fire News No.17, 33-37.

Roads, J., S.-C. Chen, M. Kanamitsu, and H. Juang, 1998, Vertical structure of humidity and temperature budget residuals over the Mississippi River basin. J. Geophys. Res., 103, 3741-3759.

Roads, J., S.-C. Chen, M. Kanamitsu, H. Juang, 1999: Surface water characteristics in NCEP global spectral model reanalysis. J. Geophys. Res., 104, 19307-19327.

Roads, J., S.-C. Chen, F. Fujioka, R. Burgan, 2000a: Development of a seasonal fire weather forecast for the contiguous United States. Proceedings of AMS Annual Meeting, Long Beach, Ca. January 9-13, 2000.

Roads, J., S.-C. Chen, J. Ritchie, 2000b: ECPC's weekly to seasonal U.S. forecasts of FWI, soil moisture, and precipitation. ELLFB quarterly bulletin, Sept. 1998-Jun. 2000.

Roads, J., S.-C. Chen, F. Fujioka, 2001: ECPC's weekly to seasonal global forecasts. Bull. Amer. Meteor. Soc. (accepted)

Von Storch, Hans, and Francis W. Zwiers 1999: Statistical analysis in climate research, Cambridge University Press, $149 \mathrm{pp}$.

Wong, H., and G. Zhou, 1998: Prediction of 1998 summer monsoon using IAP climate model. 
Review of Climate Prediction, National Climate Center, 1998, 77-78 (in Chinese).

Xie, P., and P.A. Arkin, 1997: Global Precipitation: A 17-year monthly analysis based on gauge observations, satellite estimates, and numerical model outputs. Bull. Amer. Meteor. Soc., 78, 2539-2558.

Yuan, J., and X. Wu, 1998: Evaluation of statistical approaches in climate forecast. Review of Climate Prediction, National Climate Center, 1998, 171-175 (in Chinese). 